\title{
Activated natural killer cell-mediated immunity is required for the inhibition of tumor metastasis by dendritic cell vaccination
}

\author{
Aeyung Kim ${ }^{1}$, Young-Woock Noh ${ }^{1}$, \\ Kwang Dong Kim ${ }^{1}$, Yong-Suk Jang ${ }^{2}$, \\ Yong-Kyung Choe ${ }^{1}$ and Jong-Seok Lim ${ }^{1,3}$ \\ ${ }^{1}$ Laboratory of Cell Biology \\ Korea Research Institute of Bioscience and Biotechnology \\ Daejeon 305-600, Korea \\ ${ }^{2}$ Department of Biology \\ Chonbuk National University \\ Chonju 561-181, Korea \\ ${ }^{3}$ Corresponding author: Tel, 82-42-860-4193; \\ Fax, 82-42-860-4593; E-Mail, jslim@kribb.re.kr
}

Accepted 21 September 2004

Abbreviation: DCs, dendritic cells; NK, natural killer

\begin{abstract}
Immunization with dendritic cells (DCs) pulsed with tumor antigen can activate tumor-specific cytotoxic $T$ lymphocytes (CTL), which is responsible for tumor protection and regression. In this study, we examined whether DCs pulsed with necrotic tumor lysates can efficiently prevent malignant melanoma tumor cell metastasis to the lung. DCs derived from mouse bone marrow were found to produce remarkably elevated levels of IL-12 after being pulsed with the tumor lysates. Moreover, immunization with these DCs induced CTL activation and protected mice from metastasis development by intravenously inoculated tumor cells. In addition, these DCs activated $\mathrm{NK}$ cells in vitro in a contact-dependent manner, and induced NK activities in vivo. Furthermore, NK cell depletion before DC vaccination significantly reduced the tumor-specific CTL activity, IFN $-\gamma$ production, and IFN $-\gamma$ inducible gene expression, and eventually interfered with the antitumor effect of tumor-pulsed DCs. Finally, similar findings with respect to NK cell dependency were obtained in the C57BL/ $6 \mathrm{~J}-\mathrm{bg} / \mathrm{bg}$ mice, which have severe deficiency in cytolytic activity of NK cells. These data suggest that the antitumor effect elicited by DC vaccination, at least in a B16 melanoma model, requires the participation of both cytolytic NK
\end{abstract}

and $C D 8^{+} T$ cells. The findings of this study would provide important data for the effective design of DC vaccines for cancer immunotherapy.

Keywords: cancer vaccines; cytotoxic T lymphocytes; dendritic cells; melanoma; natural killer cells

\section{Introduction}

Dendritic cells (DCs) are highly effective antigenpresenting cells with the unique ability of inducing primary immune responses against tumor-associated antigens (Banchereau et al., 2000), and have important roles in both early and late adaptive immune responses. In fact, DCs pulsed with soluble $\mathrm{Ag}$ are able to induce protective antitumor immunity accompanied by tumor-specific CTL induction in mice and humans (Nestle et al., 1998; Shibagaki and Udey, 2002). Given that the induction of stronger CTL responses is a major goal of current cancer vaccine strategies, tumor lysate-loaded DCs containing multiple known and unknown antigens that can be presented to $\mathrm{T}$ cells by both MHC class I- and class II-pathways provide the potential to induce efficient antitumor immune responses (Nouri-Shirazi et al., 2000; Sauter et al., 2000; Kotera et al., 2001).

NK cells are the major lymphocytes of innate immune response and are able to kill tumor cells in vitro (Trinchieri, 1989). Although they have also been shown to kill circulating tumor cells in vivo, and in this way participate in the defense against establishment of metastasis (Salup et al., 1985; Wiltrout et al., 1985), it is the current paradigm that NK cells do not attack and destroy established solid tumors. This notion is based on infrequent findings of NK cells in solid tumors (Coca et al., 1997), and by the inability of biological response modifier-activated NK cells to influence the growth of established tumors (Hanna, 1982). This may indicate that NK cells do not constitute an important factor in immune reactions against established cancer. However, recent attention has been focused on the interactions between NK cells and DCs, and on the consequences of such communication during immune response. In particular, the role of DCs in innate immunity related with NK cells has only recently been investigated, and evidence indicates a substantial level of interaction and cross-regulation between NK cells and DCs (Fer- 
nandez et al., 1999; Yu et al., 2001; Piccioli et al., 2002; Andrews et al., 2003). Nevertheless, little data is available to prove that DCs activate NK cells to induce antitumor immunity. We and other groups have previously reported that the injection of DC cocultured with tumor cells can activate NK cells in vivo (Kim et al., 1999), and that the in vivo depletion of NK cells results in a marked reduction in tumorspecific CTL activity (Kim et al., 2001; Nakamura et al., 2004). Overall, these findings suggest that the initiation of innate immune responses by NK cells in cooperation with DCs facilitates CTL developments.

In this report, we describe the results of experiments designed to answer the question as to whether NK cell activity is a prerequisite for the induction of antitumor immune response by DC vaccination, in particular to the induction of tumor-specific $T$ cell response. We took advantage of the fact that B16 melanoma lung metastasis by intravenous injection occurs in NK cell-dependent way, and that tumor formation can be eliminated by activated CTL (Xu et al., 2004). We demonstrate here that DCs pulsed with necrotic tumor lysates, which are transformed into significant IL-12 producers, can efficiently prevent the lung metastasis of melanoma cells and markedly activate NK cells in vitro and in vivo. Importantly, NK cell depletion before DC vaccination significantly reduced tumor-specific CTL activity, IFN- $\gamma$ production, and IFN- $\gamma$-inducible gene expression, and eventually interfered with the antitumor effect of tumor-pulsed DCs. Similar observations were made in C57BL/ $6 \mathrm{~J}-\mathrm{bg} / \mathrm{bg}$ mice, which have severe deficiency in cytolytic activity, but not in the IFN- $\gamma$ producing activities of NK cells. In summary, our data suggest that the antitumor effect elicited by $D C$ vaccination requires, at least in a B16 melanoma model, the participation of both cytolytic NK and $\mathrm{CD}^{+} \mathrm{T}$ cells.

\section{Materials and Methods}

\section{Mice and tumor cell lines}

Five- to six-week-old female C57BL/6 mice were purchased from the Genetic Resources Center, KRIBB (Daejeon, Korea) and C57BL/6J-Lyst ${ }^{\text {bg-J }} /+$ (beige mutation) mice were provided from Prof. Je Kyung Seong, Seoul National University. A genetic mutation in the C57BL/6J-Lyst ${ }^{b-J} /+$ mouse genome accounts for the deficiency in cytotoxic activity of NK cells. These mice are of the $\mathrm{H}-2^{b}$ haplotype for histocompatibility antigens. All mice were maintained under specific pathogen-free conditions, and all experiments employing mice were performed in accordance with institutional guidelines. The B16-F10 murine melanoma cell line, which shows metastatic activity to the lungs of syngeneic C57BL/6 mice, was purchased from the American Type Culture Collection (ATCC, Rockville, MD). The YAC-1 cell line, a mouse $T$ cell lymphoma sensitive to NK cell-mediated lysis, was also purchased from ATCC. All tumor cells were cultured in RPMI containing $10 \%$ heat inactivated FBS, $100 \mathrm{U} / \mathrm{ml}$ penicillin, $100 \mu \mathrm{g} / \mathrm{ml}$ streptomycin, and $2 \mathrm{mM}$ L-glutamine (Gibco BRL, Grand Island, NY) at $37^{\circ} \mathrm{C}$ in $5 \% \mathrm{CO}_{2}$. Cells were routinely checked for the absence of Mycoplasma contamination using an ELISA detection kit (Roche Diagnostics GmbH, Mannheim, Germany).

\section{Generation of dendritic cells from mouse bone marrow cells}

Dendritic cells were generated from bone marrow cells using Dr. Inaba's method with slight modification (Inaba et al., 1992). In brief, bone marrow cells obtained from the femurs and tibias of C57BL/6 mice were incubated with an antibody cocktail containing Jij.10 (anti-CD90), J11d (anti-CD11b), 3.168 (antiCD8), GK1.5 (anti-CD4), RA3-3A1 (anti-B220), and $M 5 / 114.15 .2$ (anti-I-A ${ }^{\mathrm{b}, \mathrm{d}, \mathrm{q}} \& \mathrm{I}-\mathrm{E}^{\mathrm{d}, \mathrm{k}}$ ) at $4^{\circ} \mathrm{C}$ for $1 \mathrm{~h}$. They were then washed twice with $10 \%$ FBS RPMI and treated with rabbit complement (Low-Tox $-M$, Cedarlane, Ontario, Canada) according to the manufacturer's instructions. To eliminate dead cells, the cells were subjected to density centrifugation on Histopaque 1077 (Sigma) and then washed twice with RPMI 1640 medium without serum. They were further incubated at $5 \times 10^{5}$ cells/well in culture medium supplemented with $10 \mathrm{ng} / \mathrm{ml}$ recombinant murine GMCSF and IL-4 (Endogen, Woburn, MA) in 24-well plates (Costar, Cambridge). On days 2 and 4, nonadherent cells were discarded and culture medium was replenished with fresh DC medium. On day 7 , non-adherent cells that had acquired a typical dendritic morphology, as identified by phase contrast microscopy, were harvested by gentle swirling and then used in subsequent experiments.

\section{Induction of tumor necrosis and uptake of necrotic tumor cells by DCs}

B16-F10 tumor cell necrosis was induced by exposing the cells to one cycle of rapid freezing (liquid nitrogen) and thawing at $37^{\circ} \mathrm{C}$ in serum-free medium. After treatment all cells became trypan blue positive. For the tumor uptake by DCs, necrotic tumor cells were co-cultured with DCs at a ratio of $1: 1$ for 24 $\mathrm{h}$ at $37^{\circ} \mathrm{C}$. Phagocytosis of necrotic tumor cells by DCs was examined using a PKH-dye labeling method (data not shown).

Flow cytometric analysis of cell surface antigens To analyze DC surface molecules, $1-5 \times 10^{5}$ DCs 
were incubated at $4^{\circ} \mathrm{C}$ for $30 \mathrm{~min}$ using the following FITC-conjugated monoclonal antibodies (PharMingen, San Diego, CA): anti-CD80 (B7-1; 16-10A1), antiCD86 (B7-2; GL-1), anti-CD40 (MH 40.3), anti CD11C (N418), and anti-CD3. Dendritic cells were also stained with hybridoma culture supernatant anti-B220 (RA3-3A1/6.1), anti-I-A and I-E (M5/114.15.2), and anti-mouse macrophage (F4/80), and FITC-conjugated goat anti-rat Ig (Biosource International, $\mathrm{Ca}$ marillo, CA) was used as a secondary antibody. After washing twice with phosphate-buffered saline, flow cytometry was performed using a FACSCalibur (Becton Dickinson, Mountain View, CA).

\section{Determination of IL-12 p70 and IFN- $\gamma$ by ELISA}

To determine IL-12 p70 and IFN- $\gamma$ concentrations, cell-free culture supernatants were collected after co-culturing necrotic tumor cells with DCs, or after contacting DCs or tumor-pulsed DCs either with either C57BL/6 or beige mouse-derived NK cells, respectively. Co-cultures of DCs with NK cells were also performed in the absence or presence of different levels of anti-IL-12 neutralizing antibody C17.8 (Endogen, Woburn, MA). Cytokine levels in the culture supernatants were quantified using an ELISA Kit (Endogen) and all steps were performed at room temperature. The relationship between absorbance and cytokine concentration was linear between 0 and $1,000 \mathrm{pg} / \mathrm{ml}$, with a correlation coefficients $>0.999$, consistently.

\section{Chemokine and cytokine mRNA expression analysis by RT-PCR}

Total RNA was isolated from each sample by the acid guanidinium thiocyanate phenol chloroform extraction method. cDNA was synthesized from $10 \mu \mathrm{g}$ of total RNA using a ProSTAR ${ }^{\text {TM }}$ kit (Stratagene, La Jolla, $\mathrm{CA}$ ), and was then used as a template for PCR using the following conditions (MCP- $3 ; 94^{\circ} \mathrm{C}$ for $1 \mathrm{~min}, 57^{\circ} \mathrm{C}$ for $1 \mathrm{~min}$, and $74^{\circ} \mathrm{C}$ for $1 \mathrm{~min}, \mathrm{IL}-12 \mathrm{p} 40$ and $\mathrm{IFN}-\gamma$, $94^{\circ} \mathrm{C}$ for $1 \mathrm{~min}, 55^{\circ} \mathrm{C}$ for $1 \mathrm{~min}$, and $72^{\circ} \mathrm{C}$ for $1 \mathrm{~min}$, IP-10; $94^{\circ} \mathrm{C}$ for $1 \mathrm{~min}, 57^{\circ} \mathrm{C}$ for $1 \mathrm{~min}$, and $72^{\circ} \mathrm{C}$ for $1 \mathrm{~min}, \mathrm{Mig} ; 94^{\circ} \mathrm{C}$ for $1 \mathrm{~min}, 59^{\circ} \mathrm{C}$ for $1 \mathrm{~min}$, and $72^{\circ} \mathrm{C}$ for $1 \mathrm{~min}$ ) using specific primers. To ensure accuracy of procedure, reverse transcription (RT)-PCR was performed on the same samples using specific primers for $\beta$-actin. PCR products were harvested and resolved on a $1.2 \%$ agarose gel containing ethidium bromide and quantified with Quantity One software supplemented with Gel Doc 2000 system (Biorad, Hercules, CA). To compare relative expressions, relative values were calculated as follows; (mean concentrationxarea) of MCP-3, IL-12 p40, IFN- $\gamma$ $\mathrm{IP}-10$, or $\mathrm{Mig} /($ mean concentrationxarea) of $\beta$-actin. The sequences of the primers used were as follows:
mIL-12 p40 (forward: 5'-ATGTGTCCTCAGAAGCTAACC; reverse: 5'-CCAAATTCCATTTTCCTTCT), mIFN$\gamma$ (forward: 5'-AACGCTACACACTGCATCT; reverse: 5'-TGCTCATTGTAATGCTTGG), mMCP-3 (forward: 5'-TCCACCCTGAGGATCTCTGC; reverse: 5'-CTTCAAGGCTTTGGAGTTGG), mMig (forward: 5'-ATCTTCCTGGAGCAGTGTGG; reverse: 5'-GATTCAGGGTGCTTGTTGGT), and mIP-10 (forward: 5'-CACCATGAACCCAAGTGC; reverse: 5'-TCCAGTTAAGGAGCCCTTTT).

\section{Immunization of mice and lung metastasis identificaiton}

B16-F10 cells ( $>95 \%$ viable by trypan blue exclusion assay) were suspended at a concentration of $1.5 \times$ $10^{6} / \mathrm{ml}$ in PBS, and then injected intravenously into a lateral tail vein of $\mathrm{C} 57 \mathrm{BL} / 6$ or beige mice (200 $\mu \mathrm{l} /$ mouse). On day 17 post-injection mice were euthanized, and lungs and livers were removed and examined macroscopically. Survival curves were produced by injecting mice intravenously with $3 \times 10^{5}$ B16-F10 cells in $200 \mu \mathrm{l}$ PBS and recorded over a 40-day period.

C57BL/6 mice were immunized subcutaneously with $0.5-1 \times 10^{6} \mathrm{DCs}$, or necrotic tumor cell-loaded $D C s$ in the right flank, whereas control mice were immunized with the same volume of PBS. Five days after immunization, mice were inoculated intravenously with $3 \times 10^{5}$ viable B16-F10 cells.

\section{In vivo NK cell depletion}

To deplete NK cell population, anti-NK1.1 antibodies (PK136 ascites at $500 \mu \mathrm{g}$ Ab/injection) were injected intra-peritoneally into $\mathrm{C} 57 \mathrm{BL} / 6$ mice on immunization days $-3,-1,+1$, and +3 . NK cell depletion was confirmed by FACS analysis of spleen and peripheral blood cells. In mice treated with anti-NK1.1, no decrease in the numbers of $\mathrm{CD}^{+}$and $\mathrm{CD} 8^{+}$cells was observed in spleen or peripheral blood, suggesting that $\mathrm{CD}^{+}$and $\mathrm{CD}^{+} \mathrm{T}$ cells were not affected by anti-NK1.1 antibody treatment (data not shown).

\section{Determination of cytotoxic activity}

C57BL/6 mice, C57BL/6 mice pretreated with antiNK1.1, or beige mice at $6-8$ wk age were immunized subcutaneously in the right flank with $0.5-1 \times 10^{6}$ DCs, necrotic tumor cell-loaded DCs, or PBS. To examine CTL activities, splenocytes or lymph node cells were harvested, stimulated in vitro with irradiated DCs pulsed with necrotic tumor cells for 3 days, and then used as effector cells for CTL assays. For NK assays, we used splenocytes incubated for $12 \mathrm{~h}$ in the presence of $\mathrm{IL}-2(10 \mathrm{ng} / \mathrm{ml})$. The target cells, namely, B16-F10 or YAC-1 cells, were incubated with 
$\mathrm{Na}^{51} \mathrm{CrO}_{4}\left(100 \mu \mathrm{Ci}\right.$ per $1-2 \times 10^{6}$, NEN-DuPont) for 90 min at $37^{\circ} \mathrm{C}$ with shaking every $15 \mathrm{~min}$. Radioisotope-labeled target cells were then combined with various numbers of effector cells in 96-well U-bottomed culture plates (Corning, NY) in triplicate. Wells containing only culture medium and target cells served as spontaneous ${ }^{51} \mathrm{Cr}$ release controls, whereas those containing $1 \%$ SDS and target cells served as the maximum ${ }^{51} \mathrm{Cr}$ release controls. After incubating mixed cells for $4 \mathrm{~h}$ at $37^{\circ} \mathrm{C}$ in $5 \% \mathrm{CO}_{2}$, supernatants $(100 \mu \mathrm{l})$ were collected from each well, and ${ }^{51} \mathrm{Cr}$ release was measured in a gamma counter (Wallac Inc., Gaithersburg, MD). The percentage of specific lysis was calculated as follows: (cpm of test - cpm of spontaneous release) / (cpm of maximum release $-\mathrm{cpm}$ of spontaneous release $) \times 100$. Data shown are mean results of triplicate cultures.

\section{Statistical analysis}

Data are expressed as means $\pm S D$. Statistical analysis was performed using the Student $t$-test, twosided. Differences were considered statistically significant for $P$ values $<0.05$.

A
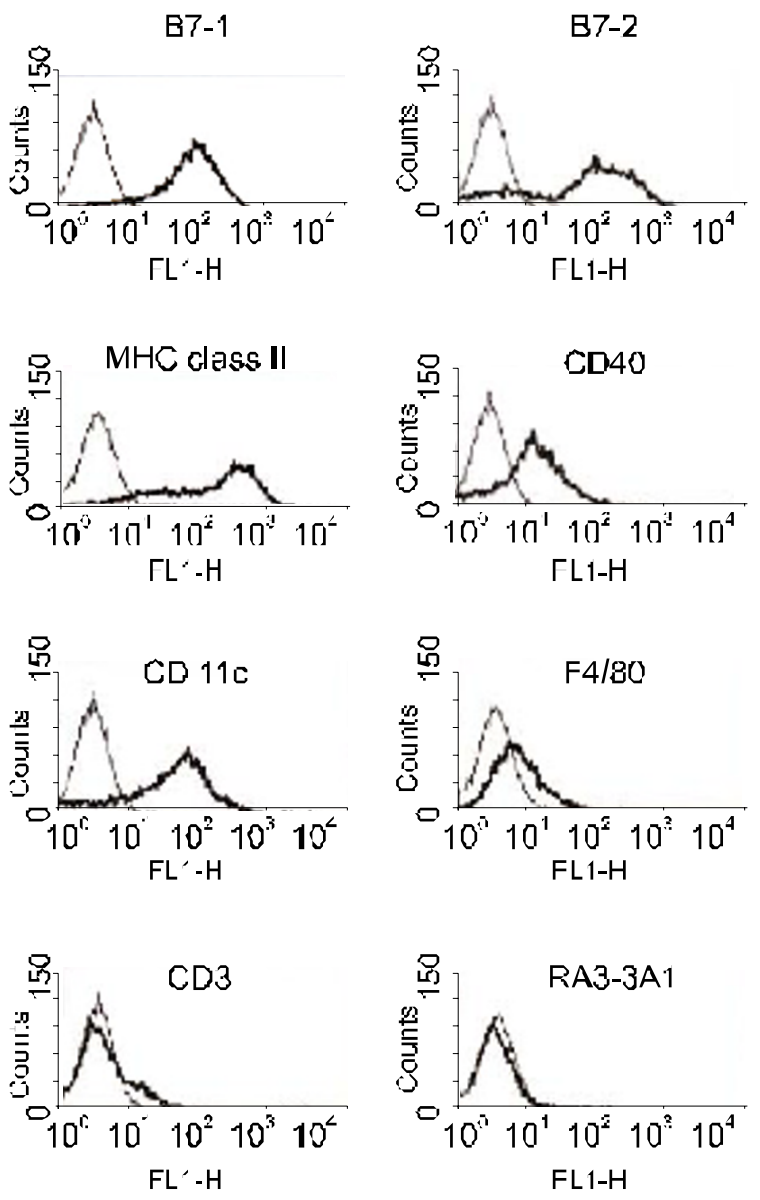

\section{Results}

Increased IL-12 production in DCs after uptake of necrotic tumor cells

Following the negative selection of precursor cells derived from bone marrow of C57BL/6 mice using antibody cocktails, DCs were generated by culture in the presence of IL-4 and GM-CSF. To determine their phenotype, DCs were subjected to flow cytometric analysis using a series of monoclonal antibodies. As shown in Figure $1 \mathrm{~A}$, the antigens CD80, CD86 and MHC class II were highly expressed, but macrophage-, $T$ cell- and $B$ cell-specific antigens were either detected weakly or not detected. CD40 and CD11c antigens were also highly expressed. We recently found that tumor lysate-pulsed DCs from Balb/c mice are able to produce significant levels of IL-12 (Kim et al., 2003). Thus, we investigated whether $\mathrm{IL}-12$ production can be induced by pulsing DCs with necrotic B16 tumor cells. Tumor cells were subjected to necrosis by one cycle of rapid freezing and thawing, and then mixed with the same numbers of DCs. Measure of IL-12 in the supernatant from the culture fluid of DCs pulsed with necrotic B16 tumor

\section{B}

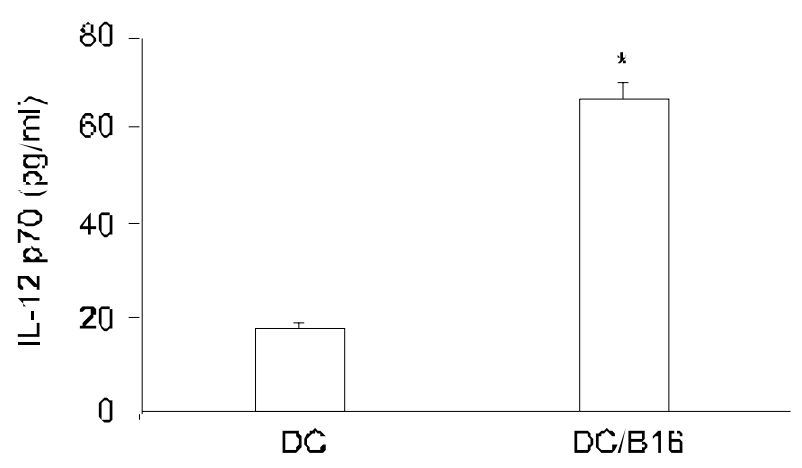

Figure 1. Tumor lysate-pulsed DCs show an enhanced ability to produce IL-12. (A) Examination of surface molecules on C57BL/6 J mouse bone marrow-derived DCs. MHC class II, B7-1, B7-2, CD40, and CD11C antigens were highly expressed on the surface of DCs, while CD3, F4/80, and B220 antigens were not detected. (B) Uptake of necrotic tumor cells induces IL-12 p70 production in DCs. DCs were co-cultured with necrotic B16 at the ratio of 1:1. After incubation for $24 \mathrm{~h}$, culture supernatants were collected, and then subjected to IL-12 p70 ELISA. The data shown are representative of a minimum of three experiments. ${ }^{*} P<0.01$ : $D C$ versus $D C / B 16$. 
cells for $24 \mathrm{~h}$ showed a greater level of IL-12 in the treated than control cells (Figure 1B). A possible endotoxin contamination was ruled out by direct the Limulus Amebocyte Lysate assay (BioWhittaker, Walkerville, $M D$ ), and also the treatment of them with polymyxin $B$ did not affect IL-12 production (data not shown).
NK cell activation and the inhibition of tumor metastasis following vaccination with tumor cell-pulsed DCs

IL-12 has been shown to directly augment the proliferation and the cytolytic potential of NK cells and to promote CTL development in mice surviving long-
A

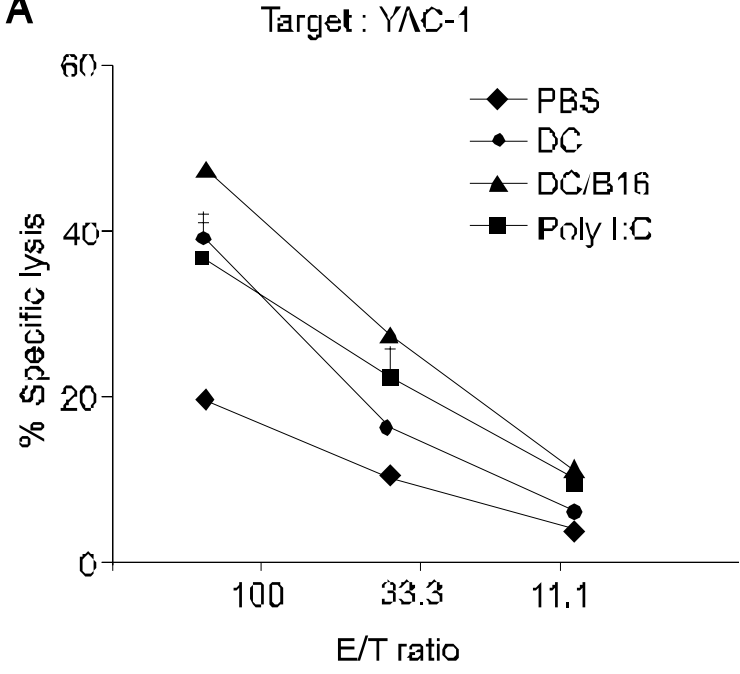

B

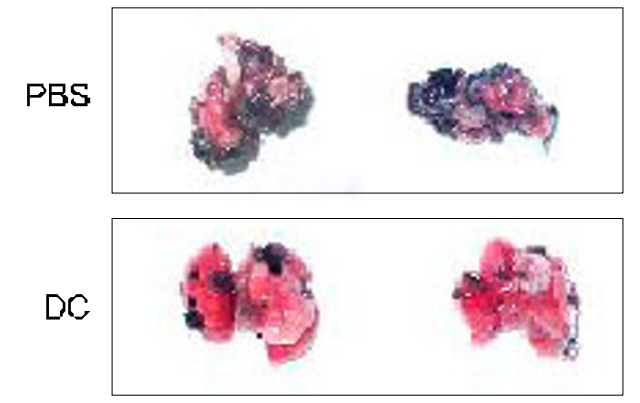

DC/B16

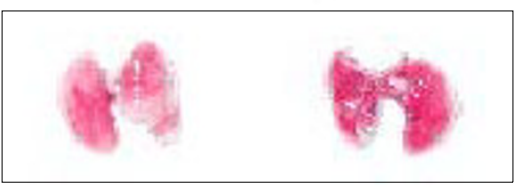

Poly I:C

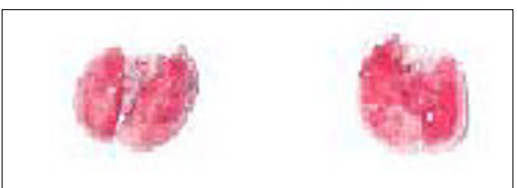

C

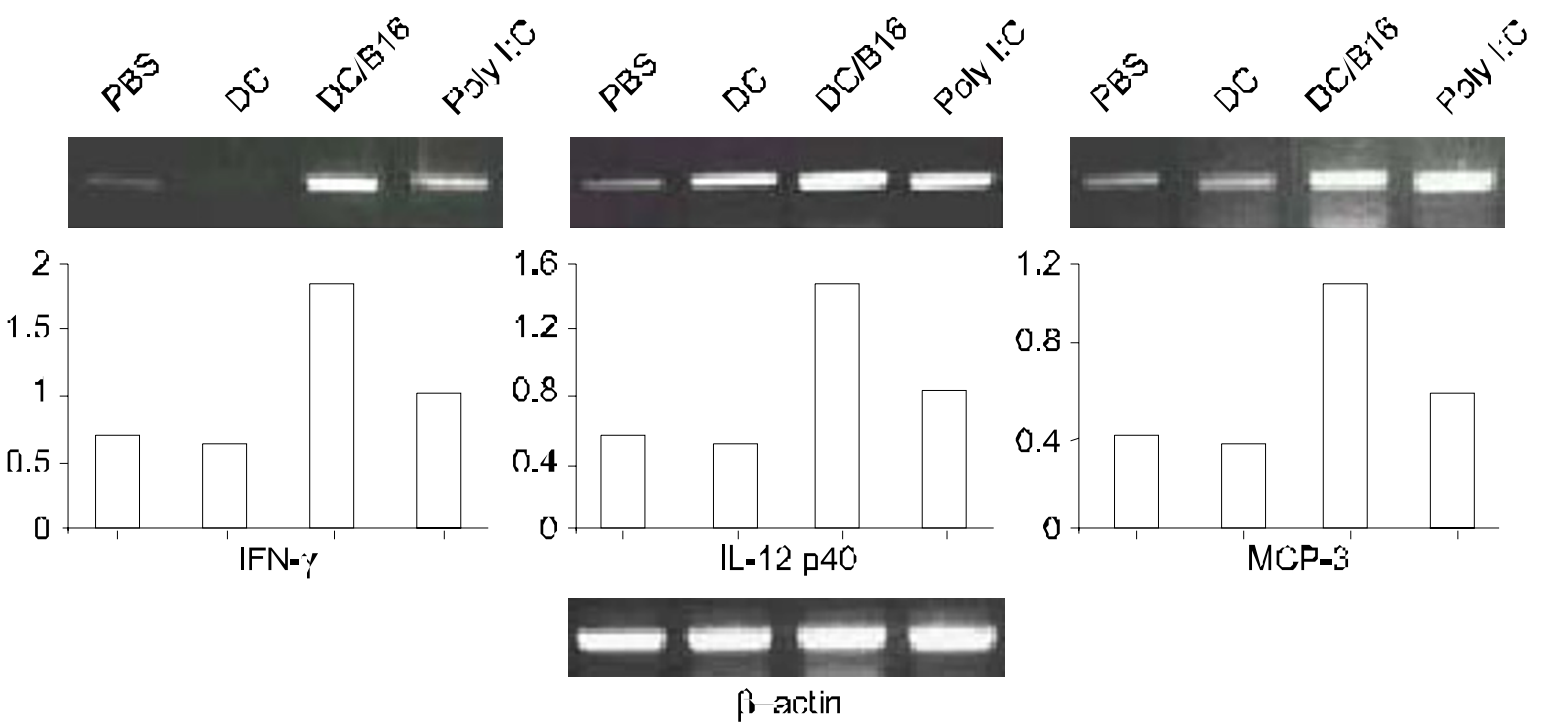

Figure 2. Activation of NK cell activity and the inhibition of tumor lung metastasis after immunizing with necrotic tumor cell-loaded DCs. (A) C57BL/6J mice were immunized subcutaneously with PBS, DC, DC/B16, or poly I:C (200 $\mu$ g/injection, intra-peritoneally, twice). After 5 days, splenocytes from each mouse were prepared, cultured for $12 \mathrm{~h}$ in the presence of IL-2 (10 ng/mI), and used as effector cells against ${ }^{51} \mathrm{Cr}-$ labeled NK-sensitive YAC-1 cells. Splenocytes from poly I:C injected mice were used immediately without additional incubation. Data are representative of two experiments that produced similar results. (B) Naive C57BL/6J mice were immunized subcutaneously with PBS, DC, or DC/B16. Poly I:C was injected intraperitoneally twice consecutively. After 5 days, viable $3 \times 10^{5}$ of B16 tumor cells were injected into lateral tail veins. On day 17 after tumor inoculation, mice were autopsied, lungs removed, and the extents of tumor metastases were observed macroscopically. Data shows lung front and rear sides. (C) C57BL/6J mice were immunized as described in A. After 5 days, spleens from immunized mice were harvested, and total RNA was extracted. RT was performed and prepared cDNAs were amplified with specific primers for IFN- $\gamma$, IL-12 p40, and MCP-3. The relative values of PCR products were calculated as follows; (mean intensityxband area) of IFN- $\gamma$, IL-12 p40, or MCP-3/ (mean intensityxband area) of $\beta$-actin. 


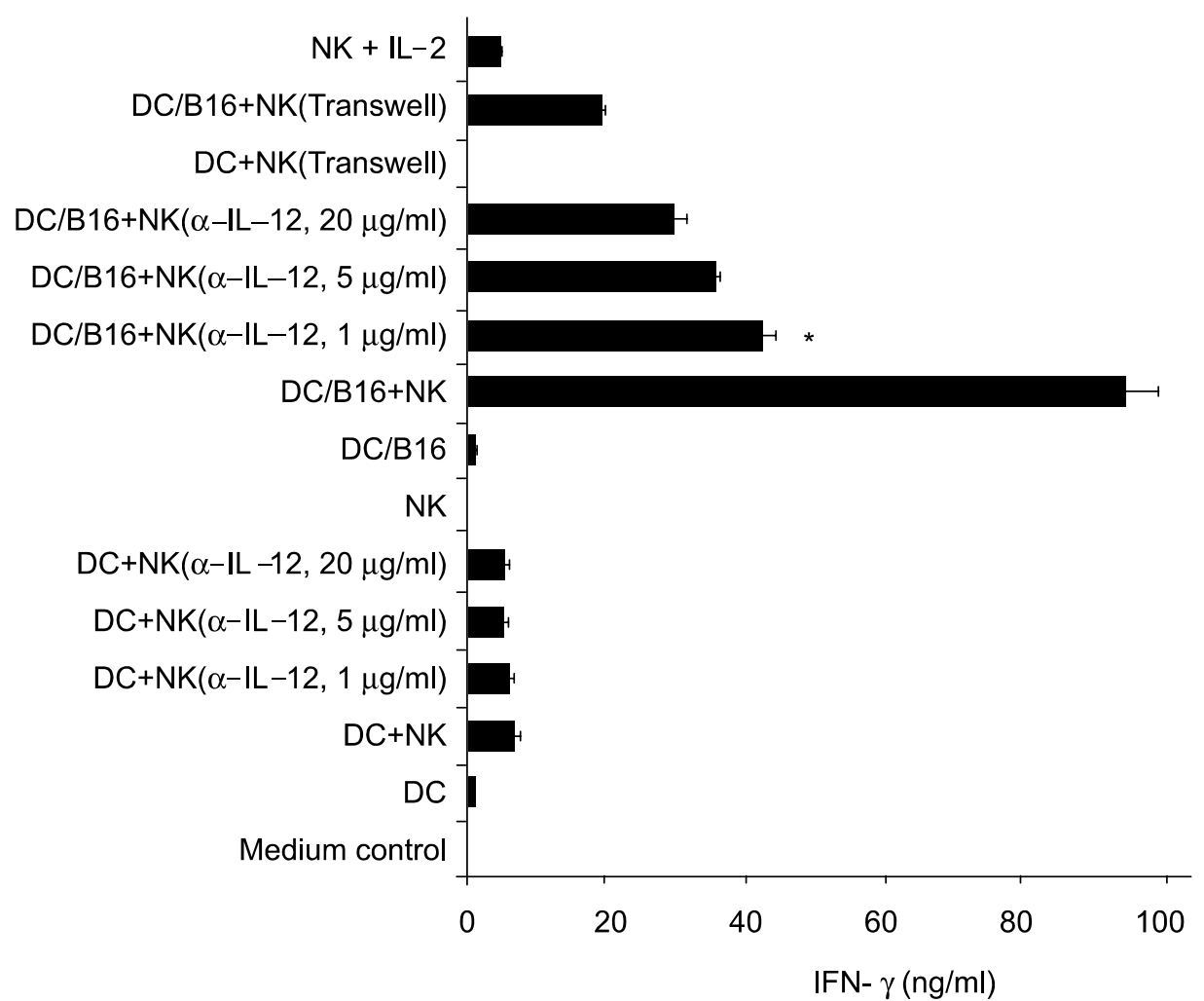

Figure 3. Co-culture of tumorpulsed DCs with NK cells in vitro enhances IFN- $\gamma$ production by NK cells in a contact-dependent manner. Naive splenic NK cells from C57BL/6J mice were negatively selected using an $A b$ cocktail (anti-CD4, CD8, B220, MHC class $\mathrm{II}$, and $\mathrm{F} 4 / 80$ ) and rabbit complement (purity $>85 \%$ ). DCs (4x $10^{5}$ ) or DCs pretreated with necrotic tumor cells for $24 \mathrm{~h}$ were thoroughly washed and co-cultured with purified splenic NK cells $(2 x$ $10^{6}$ ) under various conditions in 24-well plates for $48 \mathrm{~h}$. IFN- $\gamma$ in culture supernatant was determined by ELISA. For IL-12 depletion, different amounts of antiIL-12 neutralizing antibody were added to cultures. In some experiments, transwell plates (pore size: $0.4 \mu \mathrm{m}$, Costar, Cambridge, MA) were used to block cell-to-cell contact. Data are representative of more than three experiments. ${ }^{*} P$ $<0.01$ : without anti-IL-12 mAb versus with anti-IL-12 mAb. term (Shurin et al., 1997; Pham-Nguyen et al., 1999). Investigation of the effects of DCs or tumor-pulsed DC vaccinations on NK cell activation showed that NK cell activity on YAC-1 target cells from mice immunized with DC/B16 was considerably greater than in controls or in other immunization groups consistent with IL-12 production (Figure 2A). Furthermore, examination of $D C$ or tumor-pulsed $D C$ vaccinations effect on the pulmonary metastasis of B16 tumor cells, showed that a vaccination with tumor-pulsed DCs 5 days before tumor inoculation was enough to prevent lung metastasis 17 days after intravenous inoculation of live tumor cells (Figure 2B). Vaccination with DCs alone had a partial effect, and poly I:C which activates NK cells had a remarkable inhibitory effect (Figure 2A and B). Vaccination with tumorpulsed DCs also significantly enhanced expression of IFN- $\gamma$, IL-12 p40 and MCP-3 gene (Figure 2C). Collectively, these results suggest that vaccination with tumor- pulsed DCs induced NK cell activation and elicited a preventive antitumor immune response.

\section{Co-culture of tumor-pulsed DCs with NK cells in vitro induces NK cell activation}

To test conditions required for NK cell stimulation in vitro, IFN- $\gamma$ expression was used as a guide. Purified splenic NK cells or DCs alone were not able to produce IFN- $\gamma$ whereas co-culturing the cells induced low levels of IFN- $\gamma$ production in supernatants (Figure 3). However, DCs pulsed with necrotic B16 tumor cells induced markedly more IFN- $\gamma$ secretion by $\mathrm{NK}$ cells than non-treated DCs. IFN- $\gamma$ production was not observed in the culture supernatant of tumor cellpulsed DCs, suggesting that DCs pulsed with necrotic tumor cells do not produce IFN- $\gamma$. In addition, IFN- $\gamma$ secretion was blocked by a transwell culture of two groups of cells or by adding neutralizing anti-IL-12 antibody to the co-cultures. These results show that NK cells can be stimulated to produce IFN- $\gamma$ by tumor-pulsed DCs by cell-to-cell contact and by a soluble factor, such as IL-12.

\section{Depletion of NK cells abrogates the anti-metastatic effect of tumor-pulsed DCs}

To examine whether the elimination of NK cells in vivo affects the ability of tumor-pulsed DCs to induce protective immune responses, NK cells were depleted by administering anti-NK1.1 monoclonal antibody into mice prior to injecting DCs or tumor-pulsed DCs. Significant reductions in the NK cell populations in spleen and peripheral blood cells were confirmed 1 day after antibody injection by FACS analysis (Figure $4 \mathrm{~A})$. When cytolysis assay against YAC-1 was conducted 4 days following final antibody treatment, NK cell activity was not detected in NK cell-depleted mice, even in mice vaccinated with tumor-pulsed DCs, 
A
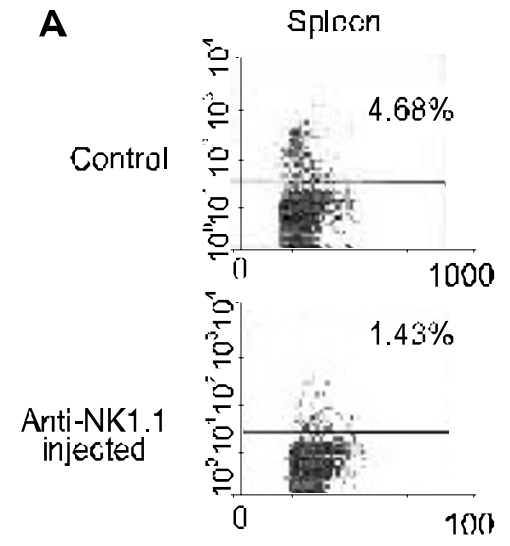

$10)$
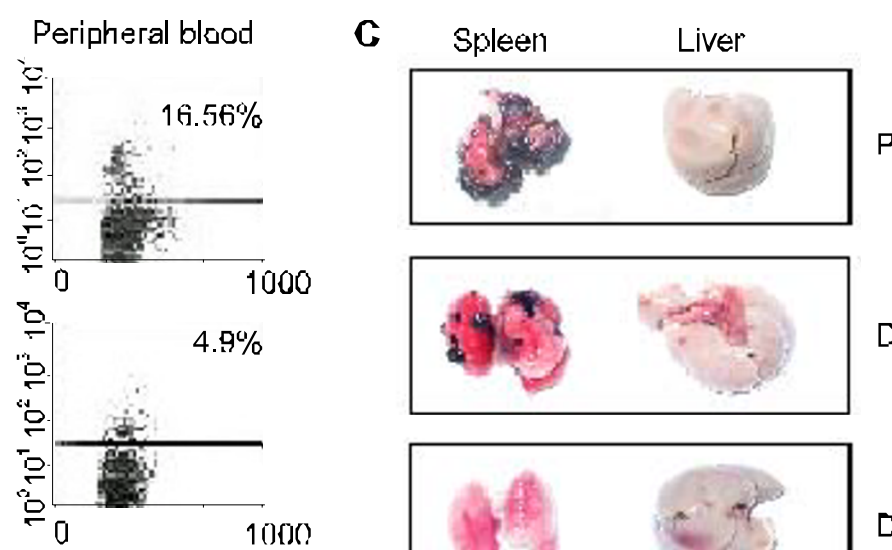

PBS
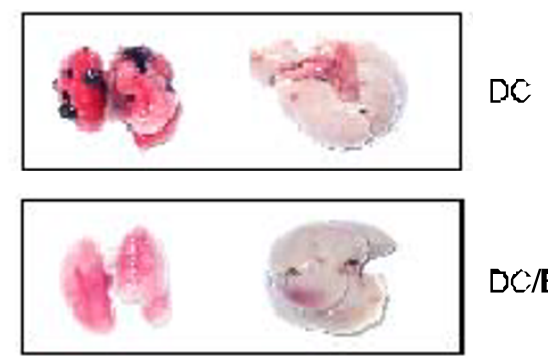

DC/B16

B

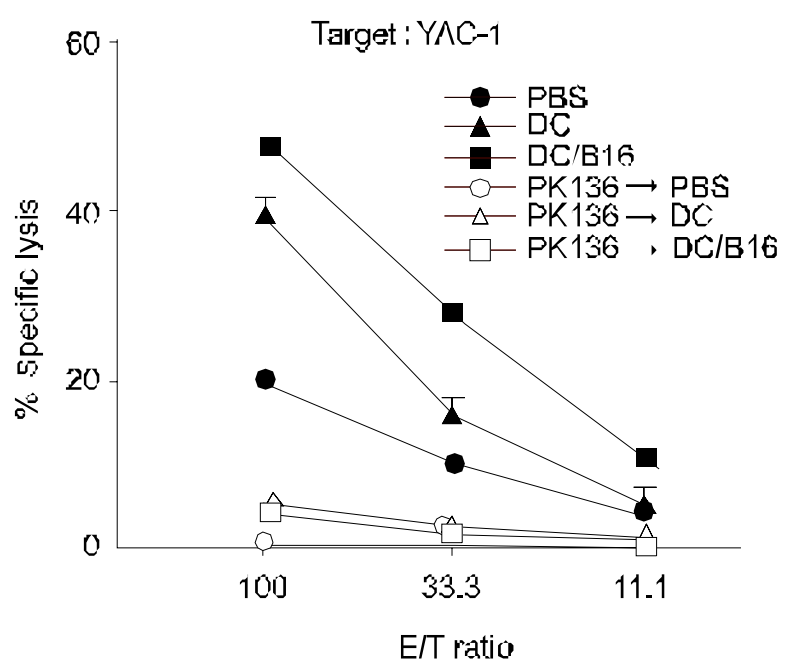

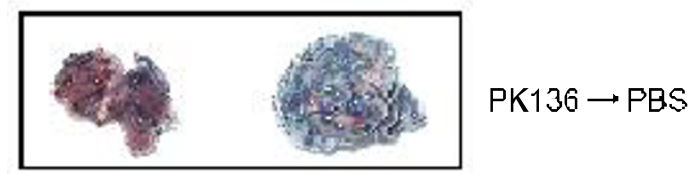
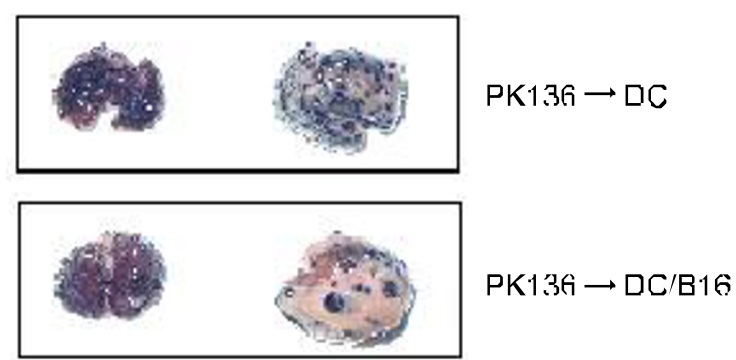

Figure 4. Pretreatment with anti-NK1.1 abrogates the anti-metastatic effect of immunization with necrotic tumor cell-loaded DCs. (A) The percentages of NK cells in splenocytes and peripheral blood cells were determined $24 \mathrm{~h}$ after intraperitoneally injecting anti-NK1.1 antibody (500 $\mu \mathrm{g}$ ) by staining with the NK-specific antibody DX-5. (B) C57BL/6J mice were immunized with PBS, DC, or DC/B16. To deplete the NK cell population, $500 \mu \mathrm{g}$ of anti-NK1.1 was injected intraperitoneally on days $-3,-1,+1$ and +3 post-immunization. After 5 days, splenocytes were prepared, cultured for $12 \mathrm{~h}$ in the presence of $\mathrm{IL}-2(10 \mathrm{ng} / \mathrm{ml})$, and used as effector cells against ${ }^{51} \mathrm{Cr}$-labeled NK-sensitive YAC-1 cells. (C) Naive C57BL/6J mice were immunized subcutaneously with PBS, DC, or DC/B16. After 5 days, $3 \times 10^{5}$ viable B16 cells were injected into lateral tail veins. To deplete the NK cell population, $500 \mu \mathrm{g}$ of anti-NK1.1 (PK136) was injected intraperitoneally 3 times every two days. 17 days after tumor injection, mice were autopsied, and lungs and livers were removed. The extents of tumor metastases were assessed macroscopically.

whereas NK cell activity was enhanced in control mice vaccinated with tumor-pulsed DCs (Figure 4B). Tumor-pulsed DCs were subcutaneously inoculated into flanks and on the fifth day, viable B16 cells were inoculated into the lateral tail vein. Anti-NK1.1 antibody for NK depletion was injected i.p. on days -3 , $-1,+1$ and +3 . As shown in Figure $4 \mathrm{C}$, at 17 days post-inoculation, the antitumor effect of $D C$ vaccination was absent in mice depleted of NK cells. In addition, liver metastasis absent in control mice was observed in all three immunized groups pretreated with antibody. The results of these experiments suggest that NK cells are required for the antitumor effect induced by immunization with tumor-pulsed DCs.
Survival of mice inoculated with tumor-pulsed DCs and the role of IFN- $\gamma$ in the antimetastatic effect of this vaccination

The effect of NK depletion on DC-mediated antitumor immune response were tested on the survival of B16 melanoma-bearing mice. Mice given intraperitoneal injections of anti-NK1.1 antibody prior to vaccination survived for 28 days on average, whereas $82 \%$ of the mice vaccinated with tumor-pulsed DCs lived over 40 days (Figure $5 \mathrm{~A}$ ). When mice that had survived more than 2 or 3 months were rechallenged with a subcutaneous injection of live tumor cells, only small tumors in a regressed state were found indicating that the vaccination had induced a long-lasting systemic 


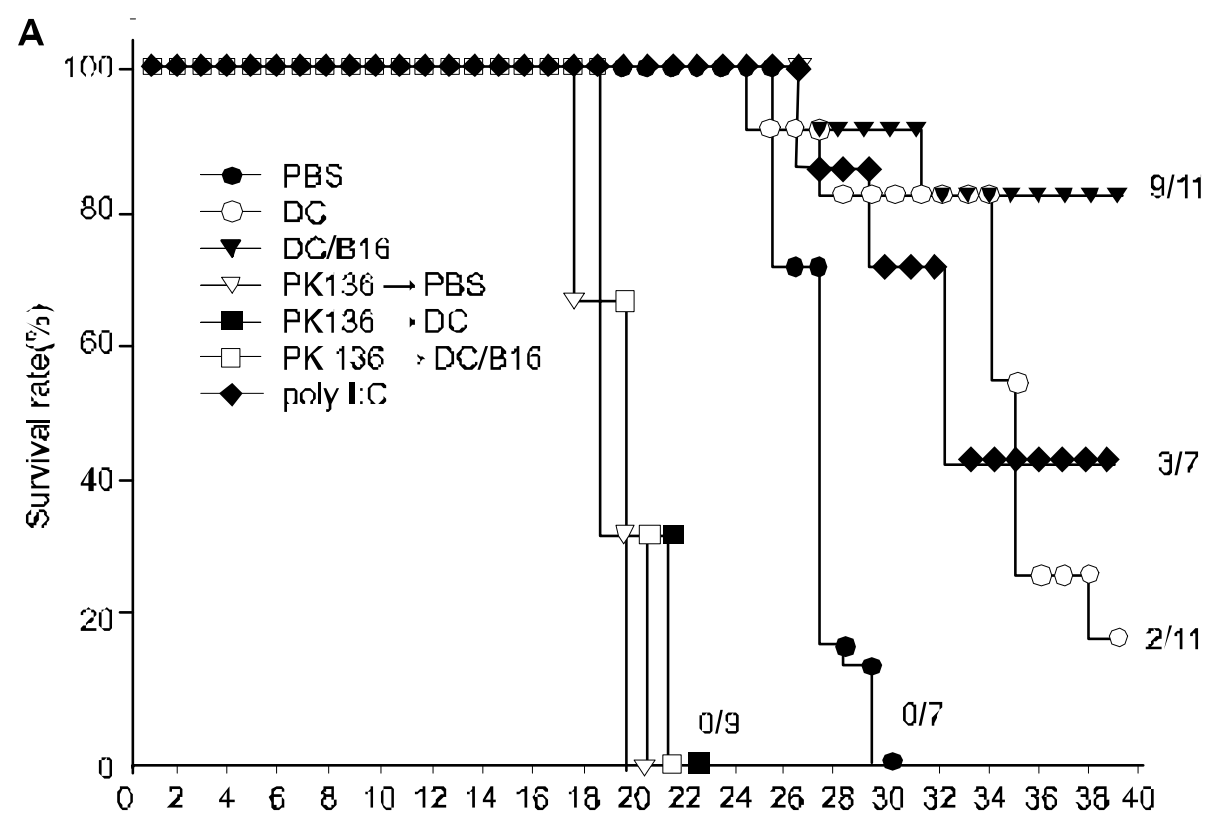

Days posl B16 F10 injeclion

B

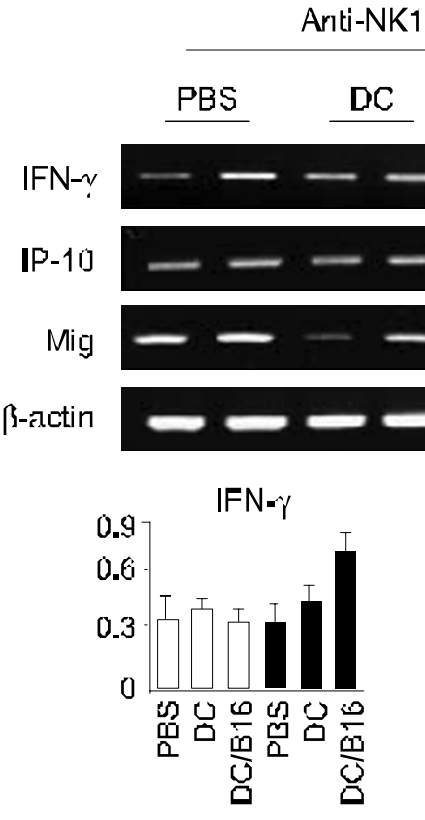

$\overline{\text { Anli-NK1.1 }}$

Arti-NK1.1

$\mathrm{DC} / \mathrm{B} 16$

PBS DC DC/B16
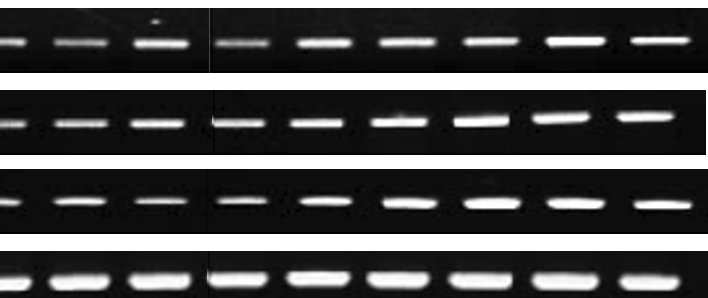

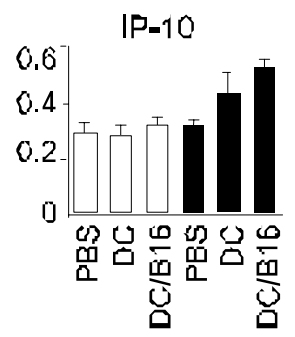

Anti-NK':
Mig

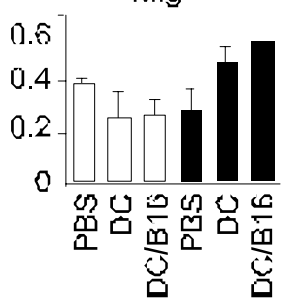

Anti-NK1.1
Figure 5. Survival of mice inoculated with melanoma and the role of IFN- $\gamma$ in the antimetastatic effect of $D C$ vaccination. (A) Naive C57BL/6J mice were immunized subcutaneously with PBS, DC, or DC/B16. After 5 days, $3 \times 10^{5}$ viable B16 cells were injected into lateral tail veins. To deplete the NK cell population, $500 \mu \mathrm{g}$ of antiNK1.1 (PK136) was injected intraperitoneally 3 times every two days. During the observation period, mice that died as a direct result of lung metastases were recorded. (B) Immunization and NK depletion were performed as described above. Total splenic RNA was extracted 5 days after immunization, and prepared cDNAs were amplified with specific primers for IFN- $\gamma$, IP-10, and Mig, respectively. To compare mean intensities, relative values were calculated as described in Figure 2. memory response mediated by $T$ cells (data not shown). The vaccination of $D C$ alone or treatment with poly I:C partially increased the survival period and survival rate of tumor inoculated mice. In contrast, irrespective of vaccination, the survival period of tumor-bearing mice after the elimination of NK cells was much shorter than that of control mice indicating that NK cells play an important role in the induction of antitumor immune responses elicited by DC vaccination.

To explore the DCs elicited effects on NK cells, the IFN- $\gamma$ and IFN- $\gamma$-inducible chemokine mRNA level in splenocytes were measured by RT-PCR analysis. An increase of IFN- $\gamma$ mRNA was observed post-5 days tumor-pulsed $D C$ vaccinated mice but not in the mice pretreated with anti-NK1.1 antibody (Figure 5B). 
Similar observations were made with respect to the expression levels of IFN- $\gamma$-inducible protein-10 (IP10 ) and monokine induced by IFN- $\gamma$ (Mig) mRNA. These data support important roles for IFN- $\gamma$ in antitumor mechanisms and suggest that NK cell depletion interferes with IFN- $\gamma$ production, which might otherwise be induced by vaccination with tumorpulsed DCs.

Induction of tumor-specific CTL by DC vaccination is implicated in long-term protection against tumor metastasis

To assess whether vaccination with tumor-pulsed DCs can induce CTL responses against melanoma cells, splenocytes or lymph node cells were isolated from mice in all groups 7 days after vaccination. These cells were then stimulated in vitro for 36 or $72 \mathrm{~h}$ with irradiated tumor cell-loaded DCs. As shown in Figure $6 \mathrm{~A}$, significant $\mathrm{CTL}$ activity was observed in mice that received tumor-pulsed DCs, whereas no specific CTL activity was detected in the anti-NK1.1 antibodytreated group. DC alone induced modest but reproducible CTL activity. Similar results were obtained when lymph node cells from treated mice were stimulated (Figure 6C). Importantly, these activities were markedly reduced by depleting $\mathrm{CD} 8^{+}$cells using anti-CD8 $\mathrm{mAb}$ and complement, indicating that the
A

$36 \mathrm{~h}$

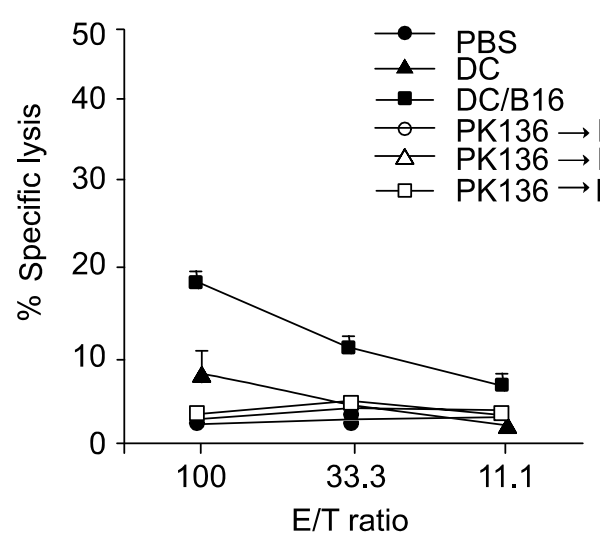

B

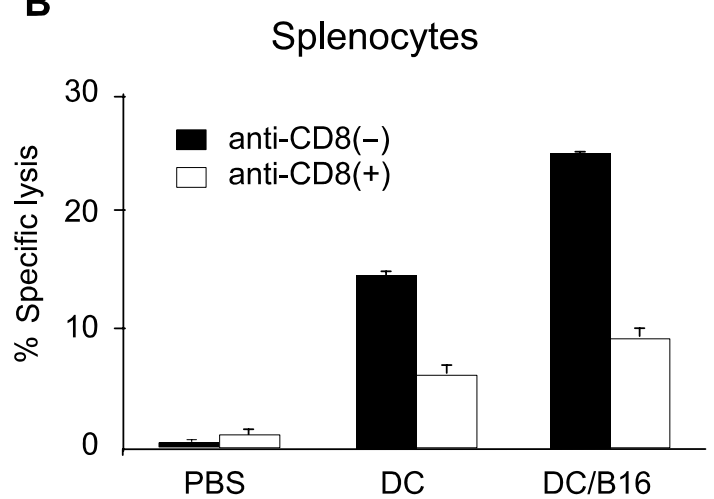

Splenocytes

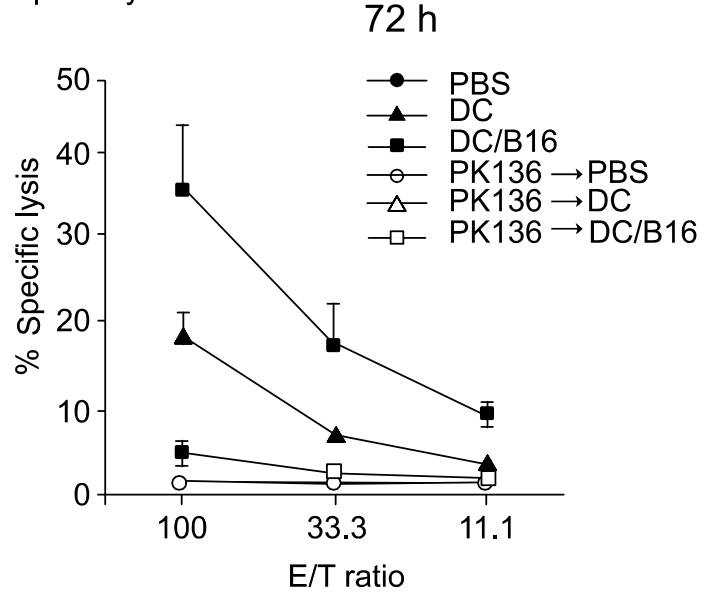

C

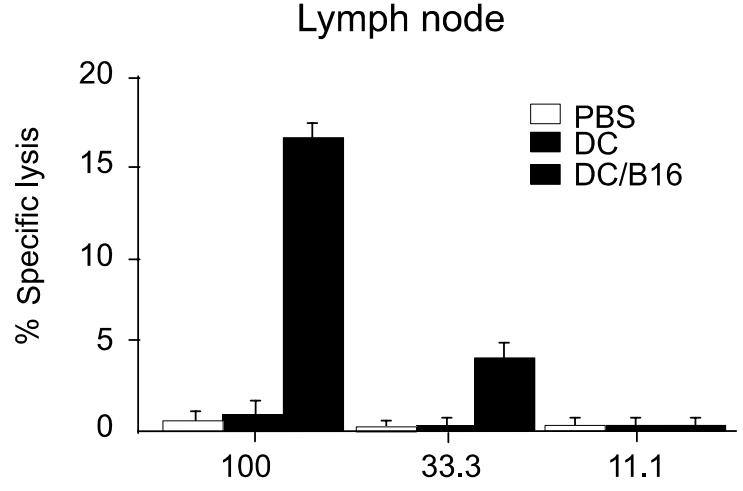

Figure 6. Induction of tumor-specific CTL after immunizing with necrotic tumor cell-loaded DCs. (A) C57BL/6 mice were immunized with PBS, $D C$, or DC/B16. To deplete the NK cell population, $500 \mu \mathrm{g}$ of anti-NK1.1 was injected intraperitoneally on days $-3,-1,+1$ and +3 post immunization. One week after immunization, splenocytes were harvested, cultured for 36 or $72 \mathrm{~h}$ with irradiated necrotic tumor cell-loaded DCs, and used as effector cells against B16 melanoma cells. Target cells labeled with $100 \mu \mathrm{Ci}$ of $\mathrm{Na}^{51} \mathrm{CrO}_{4}$ were incubated with graded numbers of effector cells in round-bottomed 96 well plates. After $4 \mathrm{~h}$, the supernatants were harvested and counted in a gamma counter. The data shown are representative of a minimum of three experiments. (B) To examine Ag-specific cytotoxicity, in vitro stimulated splenocytes from each group were treated with anti-CD8 mAb (3.168) and rabbit complement, and then used as effector cells. Depletion of $\mathrm{CD} 8^{+} \mathrm{T}$ cells by antibody was confirmed by FACS analysis (data not shown). (C) Lymph node cells were prepared from immunized mice, in vitro stimulated with irradiated necrotic tumor cell-loaded DCs for $72 \mathrm{~h}$, and then used as effector cells. Mice pretreated with anti-NK1.1 did not have any cytolytic activity, as shown in Figure $5 \mathrm{~A}$ (data not shown). 
cytotoxic activities were mainly mediated by $\mathrm{CD}^{+}{ }^{+}$ cells (Figure $6 \mathrm{~B}$ and $\mathrm{C}$ ). To identify the role of the functional NK cells responsible for antitumor activity, we vaccinated $\mathrm{DCs}$ into $\mathrm{C} 57 \mathrm{BL} / 6 \mathrm{~J}-\mathrm{bg} / \mathrm{bg}$ mice, in
A

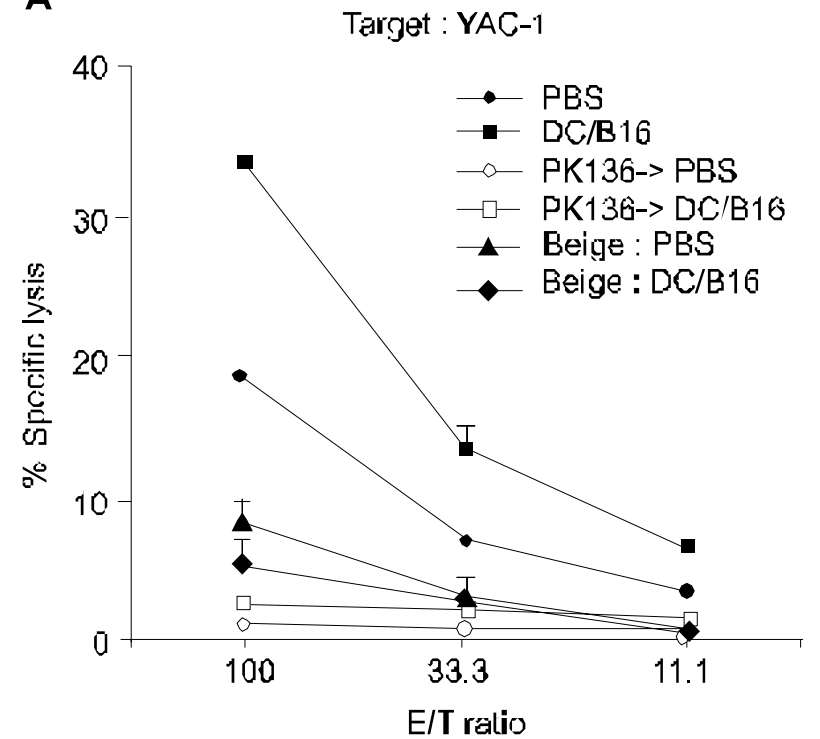

B

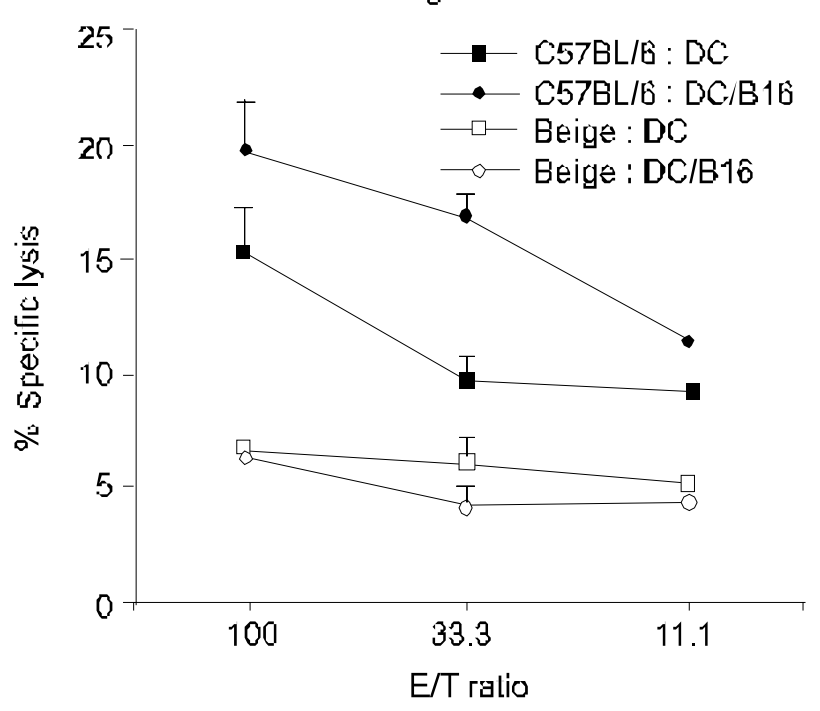

C

\begin{tabular}{|c|c|c|c|}
\hline \multicolumn{3}{|c|}{ C57BL/6 } & \multirow{2}{*}{$\frac{\text { Beige }}{\text { DC/E16 }}$} \\
\hline PBS & DC & DC/B16 & \\
\hline & & & 3 \\
\hline
\end{tabular}

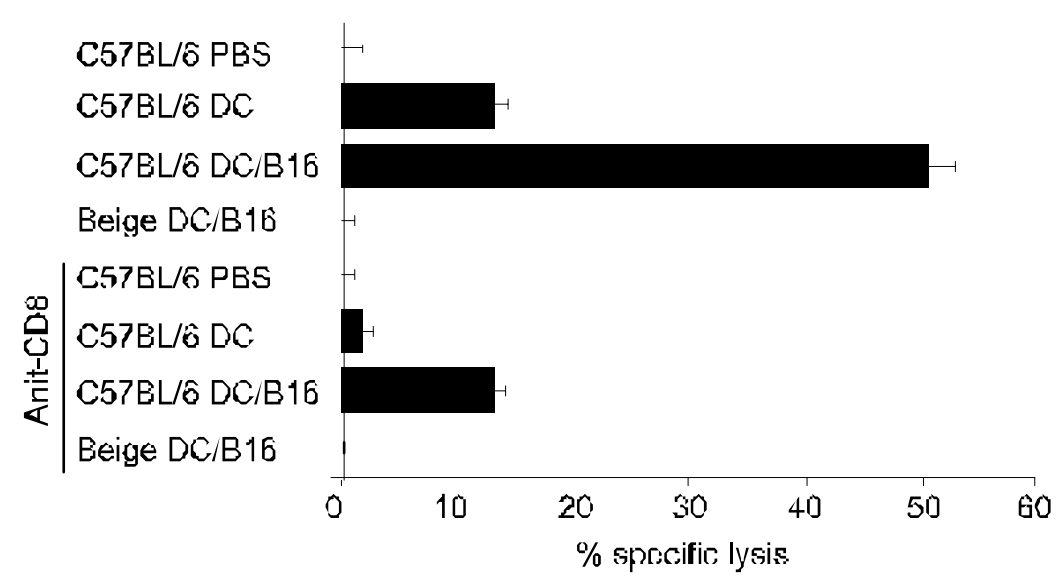

Figure 7. NK cell depletion by treating with monoclonal antibody in vivo abrogates DC vaccination effects. (A) C57BL/6, anti-NK1.1-pretreated C57BL/6, and C57BL/6J-Lyst 1 g-J $/+$ mice were subcutaneously immunized with PBS, or DC/B16. After 5 days, spleens were removed, incubated for $12 \mathrm{~h}$ in the presence of IL-2, and then used as effector cells against YAC-1 cells. (B) C57BL/6 and beige mice were subcutaneously immunized with $D C s$ or DC/B16. After 7 days, spleens were removed, incubated with irradiated DC/B16 for 3 days, and then used as effector cells against B16F10 cells. Control mice injected with PBS buffer only showed no cytolytic activity in all mice. (C) C57BL/6, anti-NK1.1-pretreated C57BL/6, and beige mice were subcutaneously immunized with PBS, DC, or DC/B16. After 5 days, $3 \times 10^{5}$ viable B16 cells were injected into lateral tail veins. On day 29 after immunization, each group of mice were autopsied, lungs were removed, and the extents of tumor metastases were assessed macroscopically. In addition, spleens were harvested, incubated in vitro for 3 days, and then used as effector cells against B16. To test the $C D 8^{+}$cell involvement in CTL activity, a part of effector cells were depleted of $C D 8^{+} T$ cell. $E / T$ ratio $=100$. 
which the cytolytic functions of NK cells are defective. As expected, no NK cytolytic activity was observed, even after tumor-pulsed DC vaccination, which was similar to the findings obtained in NK cell-depleted mice (Figure 7A). In addition, tumor-specific CTL activity induced by vaccination in the control mice was not induced in C57BL/6J-bg/bg mice (Figure 7B). The enhanced CTL activities of splenocytes from the vaccinated mice were again strongly blocked by a depletion of $\mathrm{CD}^{+} \mathrm{T}$ cells in the effector cells (Figure $7 \mathrm{C})$. In parallel with these results, pulmonary metastasis of melanoma cells in C57BL/6J-bg/bg mice was not prevented by tumor-pulsed DC vaccination. These data suggest important roles for $\mathrm{NK}$ cells and $\mathrm{CD} 8^{+}$ $T$ cells in the antitumor immune responses induced by DC vaccination, and that splenocytes from longterm surviving mice can exhibit a strong tumorspecific CTL activity.

The cytolytic function of NK cells is required for the antitumor effects of DCs

To assess whether NK cells derived from $\mathrm{bg} / \mathrm{bg}$ mice elicit any change in the cytolytic function, DCs were cocultured with NK cells in vitro, which generally results in the activation of NK cells. After co-culture with the tumor- pulsed DCs, IFN- $\gamma$ was increased significantly greater than in co-culture with the control DCs. Interestingly, no significant difference was observed in IFN- $\gamma$ production by NK cells from different sources (Figure 8B). Although IL-2-stimulated NK cells showed the strongest cytolytic activity, the killing activity of NK cells after co-culture with the tumorpulsed DCs was increased more than by co-culture with the control DCs, which is consistent with IFN- $\gamma$ production (Figure $8 \mathrm{~A}$ ). On the other hand, the cytolytic activity of NK cells derived from $\mathrm{bg} / \mathrm{bg}$ mice was still low irrespective of the presence of IL-2 or co-culture with DCs. These observations indicate that cytolytic activity of NK cells induced by DC vaccination is primarily required for antitumor immune responses and tumor prevention, despite the antitumor role played by IFN- $\gamma$.

\section{Tumor metastasis can be inhibited by therapeutic} vaccination with tumor-pulsed DCs

Therapeutic potential of the tumor-pulsed DCs vaccination on the pulmonary metastasis of melanoma cells was tested in mice model. Pulmonary metastasis was formed by an intravenous injection of viable tumor cells, and vaccination was performed by a
A

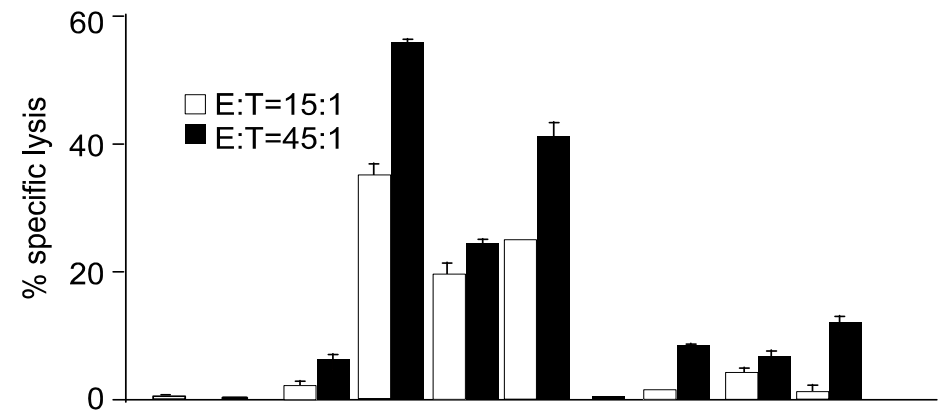

B

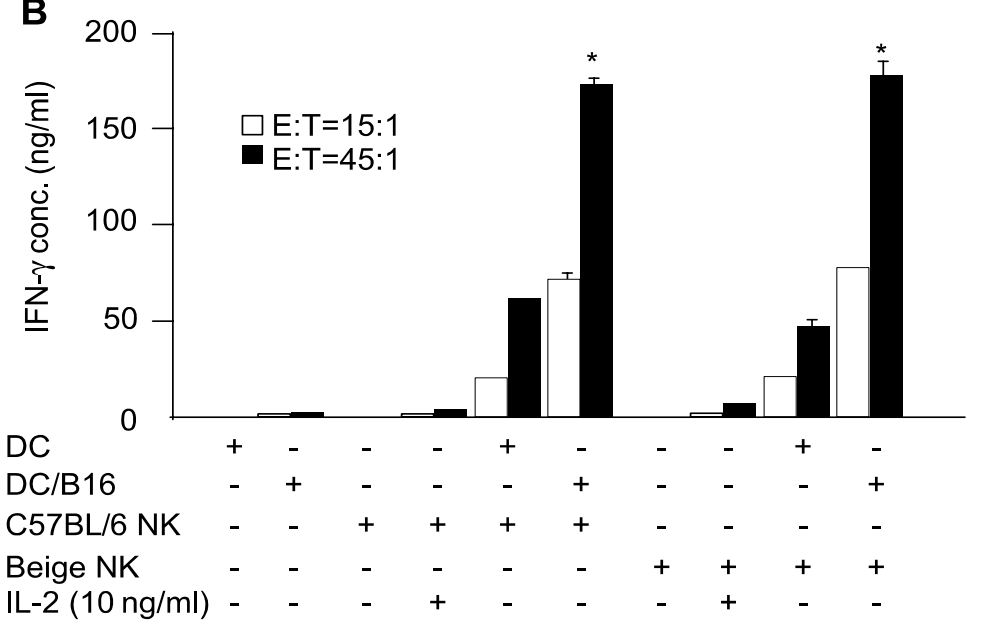

Figure 8. Co-culture of DCs and NK cells enhances IFN- $\gamma$ production by NK cells and the cytolytic activity of NK cells. (A) Splenic NK cells from C57BL/6J and $\mathrm{C} 57 \mathrm{BL} / 6 \mathrm{~J}-\mathrm{bg} / \mathrm{bg}$ were negatively selected with $\mathrm{Ab}$ cocktail (anti-CD4, CD8, B220, MHC class II, and F4/80) and rabbit complement. DCs or DCs pulsed with necrotic tumor cells $\left(1 \times 10^{5}\right)$ for $24 \mathrm{~h}$ were thoroughly washed and co-cultured with splenic NK cells $\left(4.5 \times 10^{5}\right)$ in 96-well plates for $24 \mathrm{~h}$. Thereafter, the cultured NK cells were incubated at different ratios with $1 \times 10^{4}$ of ${ }^{51} \mathrm{Cr}$-labeled YAC-1 cells for $4 \mathrm{~h}$ before measuring their cytolytic activities by ${ }^{51} \mathrm{Cr}$-release assay. (B) The concentrations of IFN- $\gamma$ in the culture supernatants were measured using an ELISA kit. ${ }^{*} P<0.01$ : $D C$ versus DC/B16. 
A

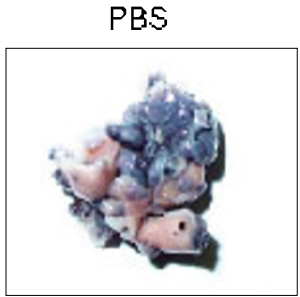

B16

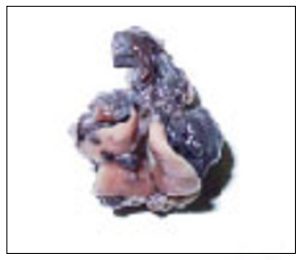

DC

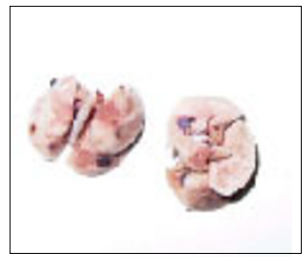

DC/B16

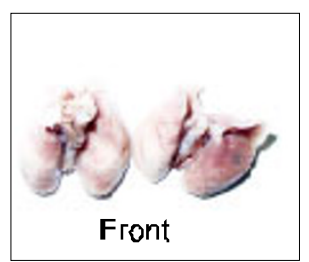

DC/B16

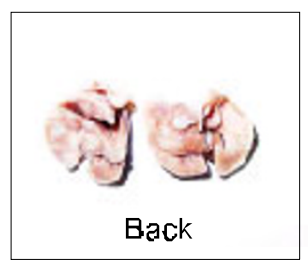

B

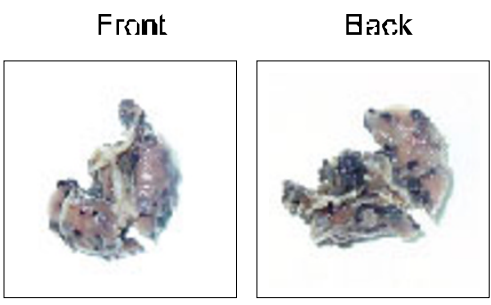

PBS
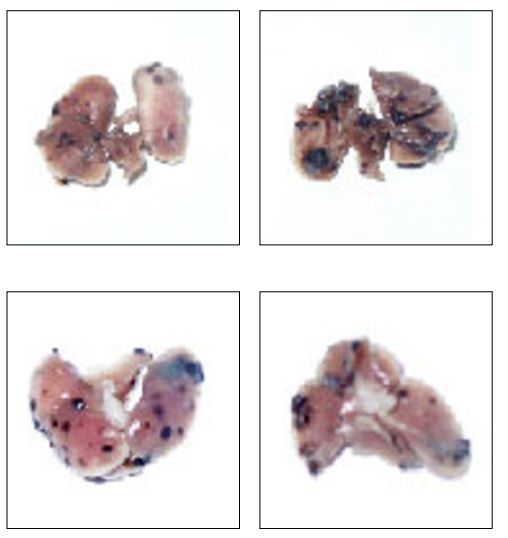

B.16

Front
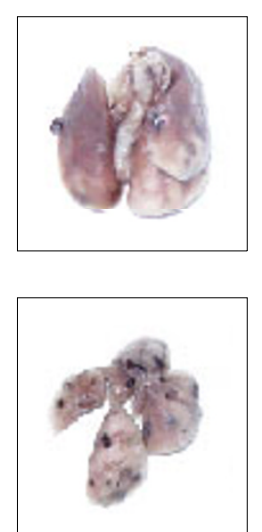

DC
Back
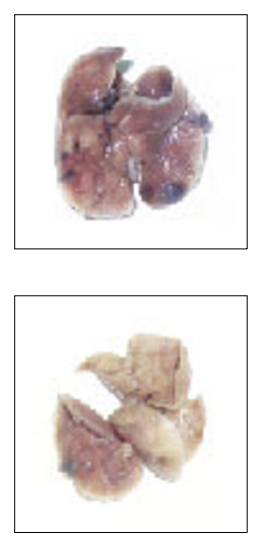

Front
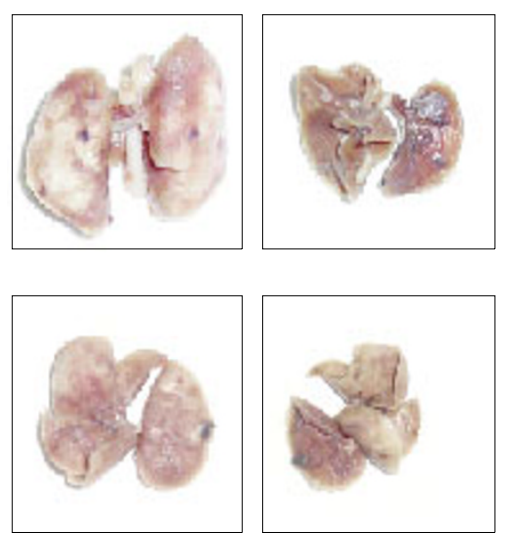

DC/B16
Back

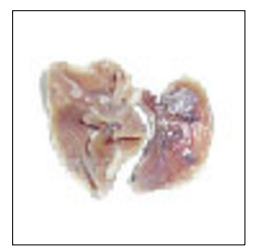

Figure 9. Therapeutic vaccination of tumor-pulsed DCs significantly inhibits pulmonary metastasis by B16 melanoma tumor cells. (A) Pulmonary metastases were formed by intravenously injecting $3 \times 10^{5}$ viable B16 cells. Vaccinations with PBS, irradiated B16, DCs or tumor-pulsed DCs $\left(1 \times 10^{6}\right)$ were performed by subcutaneous injection into the right flank on the same day. After 24 days, lungs from 2 mice per group were removed and the extents of lung metastases were assessed macroscopically. Importantly, DC therapy showed a partial, but significant inhibitory effect on pulmonary metastases. (B) Pulmonary metastases were formed by intravenously injecting $3 \times 10^{5}$ viable B16 cells. After 2 days, therapeutic vaccinations were performed by subcutaneous injection. Lungs from 2 mice per group were removed on day 17 and the extents of lung metastases were assessed macroscopically.

subcutaneous injection on the same day. When melanoma cell metastasis was assessed macroscopically after 24 days, the number of metastatic colonies was lower in mice that had received DCs and markedly more reduced in mice that had received tumor-pulsed DCs (Figure 9A). In another experiment, the therapeutic vaccination was delayed 2 days after tumor challenge, and lung metastasis was observed after 24 days. As shown in Figure 9B, vaccination with tumorpulsed DCs was still effective, although some metastatic colonies were observed, whereas the inhibitory effect of DC vaccination alone was poor. These observations suggest that immunization with $D C$ vaccine acts to induce antitumor immune responses and to prevent tumor metastasis.

\section{Discussion}

Crosstalk between DCs and NK cells is now regarded as a key component in the initiation of innate and adaptive immune responses. In addition, DC-mediated 
NK cell activation is particularly efficient, since DCs promote both effector functions and the survival or proliferation of NK cells. In the present study, we found that DCs can induce mouse NK cell activation, and that NK cells are necessary for efficient tumor protection by tumor lysate-pulsed DCs, because NK cell depletion in vivo using anti-NK1.1 antibody before tumor challenge abrogated this protection against tumor challenge. Moreover, the inoculation of beige mice, having defective NK cell function, with pulsed DCs failed to induce tumor protection.

The contribution made by NK cells to the regulation of CTL activity has been documented in a number of experimental models, e.g., the induction of virusspecific CTL (Kos and Engleman, 1996), and the priming of tumor-specific CTL (Kurosawa et al., 1995; Terao, et al., 1996). In the case of a B16 tumor model, it was shown that the depletion of NK cells before B16 immunization abrogated tumor-specific CTL activity (Kurosawa et al., 1995). However, details regarding how NK cells mediate or regulate CTL activity are not entirely clear. Moreover, there are difficulties in analyzing the NK dependence of CTL activation, because the NK specificities of antibodies used to deplete NK cells in vivo are not completely defined, and indeed, $T$ cells express $T$ cell markers as well as NK cell markers. More importantly, several studies have demonstrated that antigen-specific $T$ cells can express any of the specific NK cell markers (DX-5, NK1.1, ASGM-1, Ly49) at selective steps during CTL differentiation or activation (Ting et al., 1986; Assarsson et al., 2000; Kambayashi et al., 2001). In contrast, earlier studies demonstrated that the cytotoxic treatment of splenocytes with antiASGM-1 specifically removes NK cells, and that this treatment is ineffective at removing alloreactive cytotoxic and helper T cells (Stitz et al., 1986; Parker et al., 1988). Recent reports have also shown that antiASGM-1 depletion has no direct effect on tumorspecific CTL and does not influence the total number of splenic $\mathrm{CD}^{+}$cells (Geldhof et al., 2002; Kelly et al., 2002). Overall, these data provide evidence that the effect of antibody treatment on CTL activity is dependent on the mouse strain and/or the antigen stimulus. Thus, considering that DCs have the unique ability to activate naive $\mathrm{CD} 4^{+}$and $\mathrm{CD} 8^{+} \mathrm{T}$ cells and to sustain primary immune responses, the effect of antibody treatment for NK depletion on $\mathrm{T}$ cell activation would be expected to be negligible.

In the present study, the essential role of NK cells in the induction of efficient antitumor immune response was initially evidenced by the disappearance of tumor protection after NK cell depletion before tumor challenge. In particular, vaccination with tumorpulsed DCs enhanced NK activity, and this effect correlated well with the ability of pulsed DCs to produce IL-12 and to stimulate NK cells to produce IFN- $\gamma$ in vitro. Similar findings, which show that IL-12 has an effect on NK cell activation, were recently reported in a highly immunogenic rat histiocytic tumor (Alli and Khar, 2004). Indeed, vaccination with inactivated B16 melanoma cells showed that IL-12 is an important cytokine in mediating the development of tumor immunity (Wu and Fleischmann, 2001). It has also been shown that DCs expressing IL-12 confer NK-mediated tumor protection, and that NK activation depends on both DC-NK cellular interaction and IL-12 secretion (Miller et al., 2003). Although IL-12 shows strong antitumor activity, this activity is considered to be mediated by IFN- $\gamma$, which has already been shown to prevent B16 melanoma experimental metastasis by directly inhibiting cell growth (Kakuta et al., 2002). Recently, it was shown that IL-12-induced IFN- $\gamma$ induces IFN- $\gamma$-inducible protein-10 (IP-10) and monokine induced by IFN- $\gamma(\mathrm{Mig})$, and these chemokines have strong antiangiogenic activities, causing suppression of tumor growth (Sgadari et al., 1996; Nagai et al., 2002). These results suggest that NK cells and IFN- $\gamma$ act independently to suppress experimental metastasis.

The present study demonstrates that the expression of IFN- $\gamma$ by IL-12 secreted from pulsed DCs induces enhanced IP-10 and Mig expression. Unpulsed DCs, which induced NK activation and tumor protection in part, were unable to induce significant IFN- $\gamma$, IP-10 and Mig upregulation. Similarly, although a few mice immunized with DC alone or poly I:C had prolonged survival for more than 40 days, they were not healthy enough to be rechallenged with live tumor cells. In contrast, when surviving mice were rechallenged even after 2 or 3 months with a subcutaneous injection of live tumor cells, we observed only small tumors which then regressed, indicating that the vaccination with lysate-pulsed DCs induced a longlasting immunologic memory mediated by $T$ cells. Recently, it has been shown that fresh DC vaccination without antigen pulsing can induce NK activation and tumor protection, which was found to be NK cell mediated (van den Broeke et al., 2003). Interestingly, this activation of $\mathrm{NK}$ cells was $\mathrm{CD} 4^{+} \mathrm{T}$ cell-dependent and strongly relied on the expression of costimulatory molecules on DCs, but did not require the expression of IL-12 or IL-15 by DCs. It was concluded that, though endogenous release of IL-12 derived from the inoculated DCs themselves is not required for NK cell activation, $\mathrm{CD}^{+} \mathrm{T}$ cells are capable of bridge-forming between DCs and NK cells. Actually, it seems possible that $\mathrm{CD}^{+} \mathrm{T}$ cells may have played a similar role in our experiments, although we did not test the effect of $\mathrm{CD}^{+} \mathrm{T}$ cell depletion. As we have seen the neutralizing effect of anti-IL-12 antibody in vitro on the production of IFN- $\gamma$ by NK cells, the antitumor effect 
of tumor-pulsed DCs is expected to have been mediated through enhanced IL-12 production by pulsed DCs. However, if this was the case, the substantial effect observed after vaccinating with DCs alone, which produced only marginal levels of IL-12, cannot be explained. Thus, although the production of IL-12 has a synergistic effect on the antitumor effect induced by $D C$ vaccination, we conjecture that IL-12 production alone may not be sufficient for effective vaccine, and that cell contact between DCs and NK cells is more important for NK cell activation. The importance of cell contact for NK cell activation was evidenced by the transwell plate experiment, which allowed the two cell populations to be separated. Finally, in addition to the production of IFN- $\gamma$ by NK cells due to contact-dependent pulsed DCs stimulation, the cytolytic activities of NK cells appear to be necessary for effective tumor protection, because NK cells from beige mice could be induced to produce IFN- $\gamma$ by in vitro co-culture with DCs, whereas mice, like NK-depleted normal mice, were not protected against tumor metastasis by vaccination with pulsed DCs. Indeed, we observed that the tumor protective effect was partially recovered in beige mice after they were replenished with NK cells of normal mice activated with pulsed DCs before vaccination (data not shown). Exactly how DC-mediated NK cytolytic activity or IFN- $\gamma$ production enhancement contributes to the induction of antigen-specific CTL in individual tumor models remains to be determined.

With respect to the therapeutic benefit of $D C$ inoculation, we found that tumor-pulsed DCs offer significant partial protection by. However, it should be noted that although this treatment did not eradicate whole tumors, the observed therapeutic benefit is of importance since we treated mice bearing i.v. injected tumors by injecting pulsed DCs subcutanously. In contrast to the systemic application of DCs, the therapeutic potential of intratumoral injected $D C s$, via the induction of $\mathrm{Ag}$-specific $\mathrm{CD}^{+} \mathrm{T}$ cells, is generally accepted and is relatively well documented (Kikuchi et al., 2000; Candido et al., 2001). Our findings may therefore be valuable for the prevention of metastasis after primary tumor resection, as was demonstrated by the prevention of pulmonary metastasis in our melanoma tumor model.

Taken together, our data show that DCs are uniquely enable to activate NK cells and that they are involved in the development and maintenance of antitumor CTL. We demonstrate the importance of the relationship between $\mathrm{IL}-12$ secreting $\mathrm{DCs}$ and $\mathrm{NK}$ cells in four different ways: 1) by coculture of DCs and purified NK cells in vitro; 2) by analysis of NK cell activation in treated mice; 3 ) by depleting NK cells in tumor survival experiments; and finally 4) by immunizing pulsed DCs in beige mice. Furthermore, the finding that therapeutic benefit was observed in a metastasis model by the administration of antigenpulsed DCs, suggests the immunological relevance of the clinical application of DC vaccines. Thus, the present study may have important implications for the design of DC vaccines for cancer immunotherapy.

\section{Acknowledgment}

This study was supported by a grant (02-PJ1-PG1021206-0002) from Ministry of Health and Welfare and a Korean Food and Drug Administration grant (04092CEL-083).

\section{References}

Alli RS, Khar A. Interleukin-12 secreted by mature dendritic cells mediates activation of NK cell function. FEBS Lett 2004;559:71-6

Andrews, DM, Scalzo AA, Yokoyama WM, Smyth MJ, Degli-Esposti MA. Functional interactions between dendritic cells and NK cells during viral infection. Nat Immunol 2003; $4: 175-81$

Assarsson E, Kambayashi T, Sandberg JK, Hong S, Taniguchi M, Van Kaer L, Ljunggren HG, Chambers BJ. $\mathrm{CD}^{+} \mathrm{T}$ cells rapidly acquire NK1.1 and NK cell-associated molecules upon stimulation in vitro and in vivo. J Immunol 2000;165:3673-9

Banchereau J, Briere F, Caux C, Davoust J, Lebecque S, Liu YJ, Pulendran B, Palucka K.Immunobiology of dendritic cells. Annu Rev Immunol 2000;18:767-811

Candido KA, Shimizu K, McLaughlin JC, Kunkel R, Fuller JA, Redman BG, Thomas EK, Nickoloff BJ, Mule JJ. Local administration of dendritic cells inhibits established breast tumor growth: implications for apoptosis-inducing agents. Cancer Res 2001;61:228-36

Coca S, Perez-Piqueras J, Martinez D, Colmenarejo A, Saez MA, Vallejo C, Martos JA, Moreno M. The prognostic significance of intratumoral natural killer cells in patients with colorectal carcinoma. Cancer 1997;79:2320-8

Fernandez NC, Lozier A, Flament C, Ricciardi-Castagnoli P, Bellet D, Suter M, Perricaudet M, Tursz T, Maraskovsky E, Zitvogel L. Dendritic cells directly trigger NK cell functions: cross-talk relevant in innate anti-tumor immune responses in vivo. Nat Med 1999;5:405-11

Geldhof AB, Van Ginderachter JA, Liu Y, Noel W, Raes G, De Baetselier P. Antagonistic effect of NK cells on alternatively activated monocytes: a contribution of NK cells to CTL generation. Blood 2002;100:4049-58

Hanna N. Role of natural killer cells in control of cancer metastasis. Cancer Metastasis Rev 1982;1:45-64

Inaba K, Inaba M, Romani N, Aya H, Deguchi M, Ikehara $S$, Muramatsu S, Steinman RM. Generation of large numbers of dendritic cells from mouse bone marrow cultures supplemented with granulocyte/macrophage colony-stimulating factor. J Exp Med 1992;176:1693-702 
Kakuta S, Tagawa Y, Shibata S, Nanno M, Iwakura Y. Inhibition of B16 melanoma experimental metastasis by interferon-gamma through direct inhibition of cell proliferation and activation of antitumour host mechanisms. Immunology 2002;105:92-100

Kambayashi T, Assarsson E, Chambers BJ, Ljunggren HG. Expression of the DX5 antigen on $\mathrm{CD} 8^{+} \mathrm{T}$ cells is associated with activation and subsequent cell death or memory during influenza virus infection. Eur J Immunol 2001;31:1523-30

Kelly JM, Darcy PK, Markby JL, Godfrey DI, Takeda K, Yagita $H$, Smyth MJ. Induction of tumor-specific $T$ cell memory by NK cell-mediated tumor rejection. Nat Immunol 2002;3:83-90

Kikuchi T, Moore MA, Crystal RG. Dendritic cells modified to express CD40 ligand elicit therapeutic immunity against preexisting murine tumors. Blood 2000;96:91-9

Kim A, Kim KD, Choi SC, Jeong MJ, Lee HG, Choe YK, Paik SG, Lim JS. IL-12 production and subsequent natural killer cell activation by necrotic tumor cell-loaded dendritic cells in therapeutic vaccination. Immune Network 2003;3: $188-200$

Kim KD, Kim JK, Kim SJ, Choe IS, Chung TH, Choe YK, Lim JS. Protective antitumor activity through dendritic cell immunization is mediated by $\mathrm{NK}$ cell as well as CTL activation. Arch Pharm Res 1999;22:340-7

Kim KD, Choi SC, Kim A, Choe YK, Choe IS, Lim JS. Dendritic cell-tumor coculturing vaccine can induce antitumor immunity through both $\mathrm{NK}$ and $\mathrm{CTL}$ interaction. Int Immunopharmacol 2001;1:2117-29

Kos FJ, Engleman EG. Role of natural killer cells in the generation of influenza virus-specific cytotoxic T cells. Cell Immunol 1996;173:1-6

Kotera Y, Shimizu K, Mule JJ. Comparative analysis of necrotic and apoptotic tumor cells as a source of antigen(s) in dendritic cell-based immunization. Cancer Res 2001;61: $8105-9$

Kurosawa S, Harada M, Matsuzaki G, Shinomiya $Y$, Terao $\mathrm{H}$, Kobayashi N, Nomoto K. Early-appearing tumour-infiltrating natural killer cells play a crucial role in the generation of anti-tumour T lymphocytes. Immunology 1995;85: 338-46

Miller G, Lahrs S, Dematteo RP. Overexpression of interleukin-12 enables dendritic cells to activate NK cells and confer systemic antitumor immunity. FASEB J 2003;17:72830

Nagai H, Hara I, Horikawa T, Oka M, Kamidono S, Ichihashi M. Gene transfer of secreted-type modified interleukin-18 gene to B16F10 melanoma cells suppresses in vivo tumor growth through inhibition of tumor vessel formation. J Invest Dermatol 2002;119:541-8

Nakamura M, Kikuchi T, Kufe DW, Ohno T. Antitumor effects of fusions composed of dendritic cells and fibroblasts transfected with genomic DNA from tumor cells. Cancer Immunol Immunother 2004;53:690-6

Nestle FO, Alijagic S, Gilliet M, Sun Y, Grabbe S, Dummer $R$, Burg G, Schadendorf D. Vaccination of melanoma patients with peptide- or tumor lysate-pulsed dendritic cells. Nat
Med 1998:4:328-321

Nouri-Shirazi M, Banchereau J, Bell D, Burkeholder S, Kraus ET, Davoust J, Palucka KA. Dendritic cells capture killed tumor cells and present their antigens to elicit tumor-specific immune responses. J Immunol 2000;165:3797-803

Parker SE, Sun YH, Sears DW. Differential expression of the ASGM1 antigen on anti-reovirus and alloreactive cytotoxic T lymphocytes (CTL). J Immunogenet 1988;15:215-26

Pham-Nguyen KB, Yang W, Saxena R, Thung SN, Woo SL, Chen SH. Role of NK and T cells in IL-12-induced anti-tumor response against hepatic colon carcinoma. Int $\mathrm{J}$ Cancer $1999 ; 81: 813-9$

Piccioli D, Sbrana S, Melandri E, Valiante NM. Contactdependent stimulation and inhibition of dendritic cells by natural killer cells. J Exp Med 2002;195:335-41

Salup RR, Herberman RB, Wiltrout RH. Role of natural killer activity in development of spontaneous metastases in murine renal cancer. J Urol 1985;134:1236-41

Sauter B, Albert ML, Francisco L, Larsson M, Somersan S, Bhardwaj N. Consequences of cell death: exposure to necrotic tumor cells, but not primary tissue cells or apoptotic cells, induces the maturation of immunostimulatory dendritic cells. J Exp Med 2000;191:423-34

Sgadari C, Angiolillo AL, Tosato G. Inhibition of angiogenesis by interleukin-12 is mediated by the interferon-inducible protein 10. Blood 1996;87:3877-82

Shibagaki N, Udey MC. Dendritic cells transduced with protein antigens induce cytotoxic lymphocytes and elicit antitumor immunity. J Immunol 2002;168:2393-401

Shurin MR, Esche C, Peron JM, Lotze MT. Antitumor activities of IL-12 and mechanisms of action. Chem Immunol 1997;68:153-74

Stitz L, Baenziger J, Pircher $\mathrm{H}$, Hengartner $\mathrm{H}$, Zinkernagel RM. Effect of rabbit anti-asialo GM1 treatment in vivo or with anti-asialo GM1 plus complement in vitro on cytotoxic $T$ cell activities. J Immunol 1986;136:4674-80

Terao $H$, Harada $M$, Kurosawa $S$, Shinomiya $Y$, Ito $O$, Tamada K, Takenoyama M, Nomoto K. The opposite effect of tumor-infiltrating natural killer cells on in vivo priming of tumor-specific $\mathrm{CD}^{+} \mathrm{T}$ cells and $\mathrm{CD} 4^{+} \mathrm{T}$ cells. Immunobiology 1996;195:172-86

Ting CC, Bluestone JA, Hargrove ME, Loh NN. Expression and function of asialo GM1 in alloreactive cytotoxic $T$ lymphocytes. J Immunol 1986;137:2100-6

Trinchieri G. Biology of natural killer cells. Adv Immunol 1989;47:187-376

van den Broeke LT, Daschbach E, Thomas EK, Andringa G, Berzofsky JA. Dendritic cell-induced activation of adaptive and innate antitumor immunity. J Immunol 2003;171:5842-52

Wiltrout RH, Herberman RB, Zhang SR, Chirigos MA, Ortaldo JR, Green KM, Talmadge JE. Role of organ-associated NK cells in decreased formation of experimental metastases in lung and liver. J Immunol 1985;134:4267-75

Wu TY, Fleischmann WR. Murine B16 melanoma vaccination-induced tumor immunity: identification of specific immune 
cells and functions involved. J Interferon Cytokine Res 2001;21:1117-27

Xu D, Gu P, Pan PY, Li Q, Sato Al, Chen SH. NK and $\mathrm{CD}^{+} \mathrm{T}$ cell-mediated eradication of poorly immunogenic B16-F10 melanoma by the combined action of IL-12 gene therapy and 4-1BB costimulation. Int J Cancer 2004;109:
499-506

Yu Y, Hagihara M, Ando K, Gansuvd B, Matsuzawa H, Tsuchiya T, Ueda $Y$, Inoue H, Hotta T, Kato S. Enhancement of human cord blood CD34 ${ }^{+}$cell-derived NK cell cytotoxicity by dendritic cells. J Immunol 2001;166:1590-600 